\title{
Inhibition of return is not detected using illusory line motion
}

\author{
WILLIAM C. SCHMIDT \\ Dalhousie University, Halifax, Nova Scotia, Canada
}

\begin{abstract}
Inhibition of return (IOR) is the name that has been assigned to a response time (RT) delay to a stimulus presented at a recently stimulated spatial location. A commonly held explanation for the origins of IOR is that perceptual processing is inhibited and that this inhibition translates into slower RT. Three experiments with 10 subjects were used to directly test this perceptual explanation. The first two experiments assessed the level of perceptual facilitation present in the IOR paradigm using the frequency and latency of illusory line motion judgments. Contrary to the predictions of the perceptual view, the line motion and RT measures revealed only speeded processing at previously stimulated spatial locations. Experiment 3 required a simple detection response and used the same stimulus and timing parameters as those in Experiments 1 and 2. IOR was present, replicating the recent finding that judgments based on perceptual qualities of the stimulus do not demonstrate a RT delay, whereas simple detection tasks do show RT inhibition at previously stimulated locations. These findings are discussed in relation to a number of hypotheses about the origin of the RT delay.
\end{abstract}

Inhibition of return (IOR) is a delay in responding to a target, either manually or with eye movements, at a previously stimulated visual location. The effect was first discovered by Posner and Cohen (1984), who postulated that the response time (RT) delay reflected the inhibition of attention from returning to process information at locations where visual processing had recently occurred. In the standard IOR paradigm, a first stimulus (S1) appears at one of a number of possible display positions. A second stimulus, the target, then appears either at the same location as S1 or at a different location. At short S1-target stimulus onset asynchronies (SOAs less than approximately $300 \mathrm{msec}$ ), subjects detect the target faster when it appears at the same location as S1. After $200-300 \mathrm{msec}$, targets at $\mathrm{Sl}$ are detected more rapidly. IOR is observed as a delayed RT to the appearance of the target at S1 relative to responses to targets at a location that was not previously stimulated.

The functional significance of the proposed inhibitory process is apparent if one considers tasks such as visual search. A reflexive bias against returning attention to previously examined locations would aid organisms in more efficient processing of the visual field by decreasing the

This research was supported by NSERC Canada Postgraduate funding and an Honorary Izaak Walton Killam Scholarship to the author and by NSERC Canada Operating Grant A2600 to Zenon W. Pylyshyn. The author thanks all his participants and thanks Verla Schmidt and Michael Hiemstra for assisting in data collection. Ray Klein's zeal for discussion and mastery of the topic matter have been indispensable in the presentation of this work. Pierre Jolicoeur, Art Kramer, Hermann Müller, and an anonymous reviewer contributed by making constructive comments on an earlier draft. Correspondence should be addressed to W. C. Schmidt, Department of Psychology, Dalhousie University, Halifax, NS, Canada B3H 4J1 (e-mail: wes@) or.psychology.dal.ca). amount of duplicate processing that they engage in (Klein, 1988). Recently developed computational models and proposed mechanisms of attentional selection (Houghton \& Tipper, 1994; Tsotsos, 1993; Yantis \& Jones, 1991) have embraced the idea that inhibitory processes responsible for IOR act upon perceptual representations. These models have made IOR one of the phenomena to be explained by their processing framework. The present paper will refer to the inhibited attentional and perceptual explanation of IOR as the perceptual view.

Common wisdom accepts the perceptual view of IOR because this explanation exemplifies the accepted principles of mental chronometry, especially the popular notion that differences in RT can reflect specific functional components of processing. However, it should be noted that for inferences concerning RT differences as being caused by functional differences to hold, ancillary evidence should ideally be available to corroborate the origins of the RT difference (Pylyshyn, 1984; Townsend, 1992). The notion of converging operations suggests that in order for explanatory constructs to be convincing, they ought to be compatible with related data collected using a variety of methods. If the perceptual view is correct, and the IOR RT delay originates through inhibited perceptual processing, then a perceptually based dependent measure should supply ancillary evidence of delayed or sloweddown perceptual processing. Otherwise, it is highly probable that the RT delay originates through means other than the inhibition of perceptual representations or their processing.

A number of research findings using perceptually based dependent measures cast doubt on the notion that the origin of the IOR RT delay is perceptual. ${ }^{1}$ Maylor (1985) produced the first IOR study to use a dependent measure other than RT. Her study examined temporal 
order judgments (TOJs) within a standard IOR paradigm. In TOJ tasks, subjects are asked to report the initial of two temporally close signals arising from different spatial locations. Attention has been found to speed the transmission of signals arising from attended locations, resulting in the perception of prior entry for those stimuli (Hikosaka, Miyauchi, \& Shimojo, 1993a; Stelmach \& Herdman, 1991; Sternberg \& Knoll, 1973). Maylor's data suggested that IOR may be a responserelated process on the basis of an experiment showing that, in the IOR paradigm, judgments of temporal order between stimuli presented at previously stimulated and previously unstimulated locations favored the prior entry of stimuli from the former, even during the interval in which the perceptual account of IOR hypothesizes that such processing should be inhibited. Maylor's finding has been largely ignored, perhaps because her method was unfamiliar or because her study involved only 2 observers.

Posner, Rafal, Choate, and Vaughan (1985) also used a TOJ task in conjunction with a simple eye-movement task. First, one of two locations was stimulated, followed by the brightening of fixation to draw attention there. After a brief SOA, two dots appeared, one in each of the two possible stimulus locations. The dots were separated by a brief temporal interval. Subjects were instructed to move their eyes "in a comfortable direction" during eyemovement blocks and to judge the order of arrival of the target dots during TOJ blocks. The data from 8 subjects showed a bias against making saccades in the direction of the originally stimulated location, thereby replicating IOR effects with a visual-motor task. However, there was no effect of the previous stimulation on the TOJ task, leading Posner et al. (1985) to conclude that they had found further support for the view that facilitation due to orienting of attention rests upon a quite different mechanism from IOR. Again, this IOR data using a perceptual dependent measure has been largely overlooked by over a decade's worth of work on IOR, perhaps because researchers find it difficult to give up on the notion that IOR reflects what could potentially be a functionally useful attentional mechanism.

The present experiments examined the time course of perceptual processing in an IOR paradigm using the frequency of illusory line motion (ILM) as the dependent measure. Hikosaka, Miyauchi, and Shimojo (1991, 1993a, 1993b, 1993c; Miyauchi, Hikosaka, \& Shimojo, 1992) have shown that if a line is displayed with one end in the vicinity of an attended spatial location, then the line appears to be drawn away from that location. Hikosaka et al. (1993a) have demonstrated that the mechanism underlying this illusion is similar to that responsible in TOJ tasks (Stelmach \& Herdman, 1991): A byproduct of attentional cuing is the acceleration of signal transmission spatially close to the cued location, resulting in such signals reaching motion detection systems prior to signals arising from more distant spatial locations. The net result is the perception of motion away from the cue. If the RT inhibition in IOR arises from inhibited or delayed perceptual processing at $\mathrm{S} 1$, then observers should perceive illusory motion toward $\mathrm{S} 1$ in a probe line-that is, signals arising from locations nearby the locus of inhibition should arrive later in time than uninhibited signals arising from more distant locations, resulting in illusory motion toward previously stimulated spatial locations. Alternatively, perceptual inhibition might counteract attentional facilitation, resulting in subjects' detecting no motion at S1.

Because the percept of illusory motion across space is more prominent than a comparison between two spatial locations, the line motion illusion is a more salient and, hence, more sensitive indicator of perceptual processing than is the TOJ task (Hikosaka et al., 1993a). Furthermore, because the ILM task is simultaneously sensitive to multiple spatial locations (Schmidt, Fisher, \& Pylyshyn, 1996), a single probe is capable of assessing the simultaneous presence of facilitation and inhibition at multiple locations.

Although preliminary investigations have confirmed that ILM is attention-sensitive, some debate is beginning around this issue. Downing and Treisman (1995, in press) have proposed a functional (as opposed to mechanistic) explanation of ILM, in which they claim that apparent motion impletion processes, rather than a gradient of arrival times, are responsible for the illusion. Regardless of the utility of this argument (see Schmidt \& Klein, 1996), even Downing and Treisman (in press, Experiment 2A) have found evidence that ILM is attention-sensitive.

In Experiments 1 and 2, the frequency of ILM reported was used to gauge the facilitation and inhibition of perceptual processing at display locations that may or may not have been previously stimulated in an IOR paradigm. In addition, RT data were collected on subjects' judgments. Experiment 3 acted as a control experiment, demonstrating that the same stimulus parameters used in Experiments 1 and 2 give rise to IOR with an RT dependent measure when only a simple detection response is required of subjects.

\section{EXPERIMENT 1}

If the inhibition in IOR acts on perceptual representations, then, during the normal IOR time course, ILM away from S1 would not be expected to occur more frequently than away from the location opposite to S1. In addition, judgment RT based on those inhibited perceptual representations would be expected to be delayed as in the perceptual IOR framework. In contrast, if IOR does not inhibit perceptual representations, then ILM would be expected to occur away from $\mathrm{Sl}$ under conditions that are known to invoke IOR. Additionally, judgment RT based upon facilitated perceptual representations should be faster or at least not slower than judgments based upon unfacilitated perceptual representations. Experiment 1 directly tested these predictions by examining the 
time course of perceptual processing in the IOR paradigm, using both the frequency of line motion and associated RT for the motion judgments as dependent measures.

On each trial, the subject was presented with a stimulus (S1) in one of two possible display locations. After an interstimulus interval (ISI) that previous IOR experiments have found to be long enough to invoke IOR (SOAs greater than $300 \mathrm{msec}$ ), a probe line appeared connecting one of the locations with the center of the display (see Figure 1). Observers reported whether or not they perceived the line to be drawn toward the center of the display. If motion toward the center of the display had been perceived, then facilitation at the probed display location was inferred; otherwise, inhibition was assumed.

In order to experience ILM under normal display conditions, prior stimulation must precede the line probe by some amount of time. Excluding the prior manipulation of attention, optimal ILM appears to occur with ISIs in the range of 100-150 msec. Psychophysical pilot studies that I have carried out suggest that a minimal ISI of $3 \mathrm{msec}$ is required for most observers; otherwise, no illusory motion is experienced. This observation is important for two reasons: First, it raises the possibility that the restimulation of $\mathrm{S} 1$ is required in order for perceptual inhibition to set in; probing an empty previously stimulated location may not yield a fair appraisal of IOR. Second, the finding that there is a threshold ISI before ILM occurs raises the possibility that there may also be some delay after the restimulation of a location before the effects of IOR can be detected. Therefore, simply probing a previously stimulated location may not reveal perceptual effects of IOR if they are present.

Measures were taken in the present experiments to examine the situations where restimulation of S1 occurs and where the target duration is varied, in case such factors play a role in invoking perceptual inhibition. A number of additional trials presented an actual target before the probe line appeared to assess whether restimulation of S1 would cause inhibition. In addition, the duration of the target presentation was varied in order to assess whether perceptual representations or processes become inhibited over time.

On the perceptual account of IOR, perceptual processing of the target location under any of the experimental conditions is predicted to be delayed at $\mathrm{S} 1$ relative to the location opposite to S1. If IOR does not affect perceptual

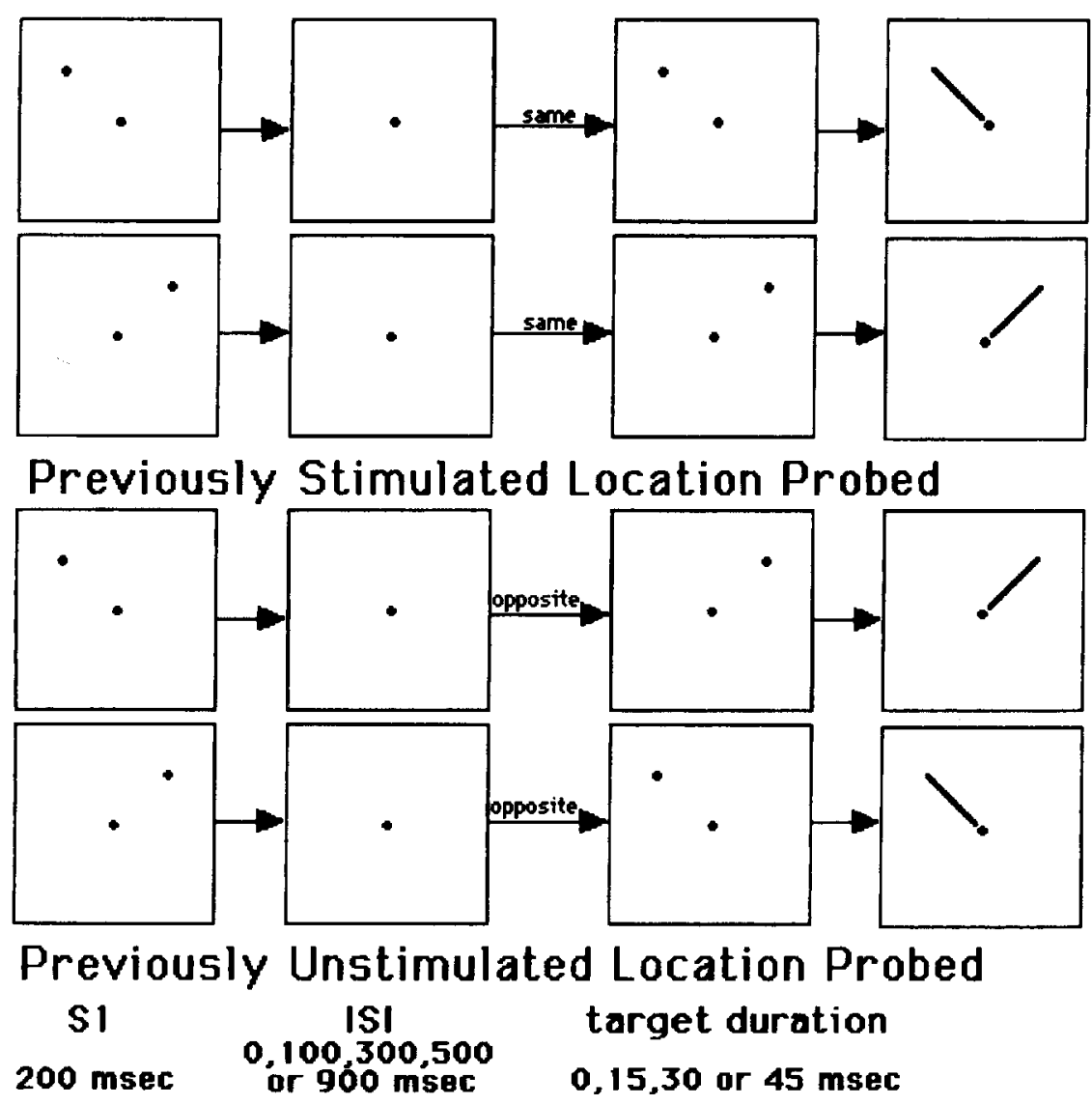

Figure 1. Experiment 1 trial sequence. Each trial began with a full field pattern for $1,000 \mathrm{msec}$, followed by the presentation of a fixation point for $800 \mathrm{msec}$. Next, S1 appeared for $\mathbf{2 0 0} \mathrm{msec}$ and was then extinguished for a variable ISI. In some conditions, the target appeared for a variable target duration, and then the probe line appeared between the probe location and the fixation point. 
processing, then no difference in phenomenological experience is expected to occur when the target appears at S1, compared with the location opposite to S1. If facilitation (defined as an increase in the speed of signal processing) should happen to exist at $\mathrm{S} 1$ as a result of prior stimulation, then ILM away from S1 would be expected to occur more frequently than motion away from the location opposite S1. Additionally, in trials presenting a target, it is expected that, after the appearance of the target and with increasing target durations, line motion away from the target location will occur more frequently because the target itself begins to attract facilitation.

\section{Method}

Observers. Ten volunteers, including the experimenter and 9 naive observers, participated in a 60 -min experimental session. All observers reported normal or corrected-to-normal vision.

Apparatus and Stimuli. The stimuli were presented on a Tektronix 608 oscilloscope equipped with a fast decay P 15 phosphor. The oscilloscope was controlled by an Interactive Electronic Systems point-plotting buffer (Finley, 1985) driven by an $80386 \mathrm{DX}$ microcomputer.

The cues and a fixation dot were composed of single points $\left(0.2^{\circ}\right)$. The fixation dot was displayed in the middle of the screen. Two possible target positions were located $3.67^{\circ}$ from the fixation dot at oblique orientations. The probe line stimulus was composed of 15 evenly spaced points forming a line $\left(2.7^{\circ}\right)$ from the fixation point to either of the two possible target positions. The line started $0.8^{\circ}$ from fixation and ended $0.18^{\circ}$ from one of the peripheral locations.

The monitor's background was a dull green and had a luminance of $0.06 \mathrm{~cd} / \mathrm{m}^{2}$. The luminance of the cues and the fixation point was $0.3 \mathrm{~cd} / \mathrm{m}^{2}$. The luminance of a section of the line was $1.2 \mathrm{~cd} / \mathrm{m}^{2}$.

A full field pattern $\left(7.5^{\circ} \times 7.5^{\circ}\right)$ composed of an array of $55 \times$ 27 evenly spaced dots $\left(0.2^{\circ}\right)$ was displayed during the intertrial interval.
Procedure. Each observer sat in a dimly lit room at a distance of $57 \mathrm{~cm}$ from the display. The observer's head was set by a headrest. Each trial was initiated by the observer's previous response or, in the case of the first trial in a block, by a simple buttonpress.

The experiment had two different types of trial, depending upon whether the target appeared at the same location as S1 or at the location opposite to $\mathrm{S} 1$. The sequence of events for each of the different trial types appears in Figure 1.

Each trial began with the appearance of a full field pattern for $1,000 \mathrm{msec}$ followed by a lone fixation point for $800 \mathrm{msec}$. $\mathrm{S} 1 \mathrm{ap}-$ peared for $200 \mathrm{msec}$ and was followed by a variable ISI $(0,100$, 300,500 , or $900 \mathrm{msec}$ ). If the trial was a no-target trial, then the probe line appeared between the fixation point and probe location. If the trial was a target trial, then the target stimulus appeared for a variable target duration $(15,30$, or $45 \mathrm{msec})$ before the probe line appeared between the fixation point and probe location.

After the probe line appeared, the observer made a judgment about the line motion by pressing a button on the computer mouse, and this initiated the sequence for the next trial. The observers were explicitly given the opportunity to take a break every 50 trials.

The observers were instructed to maintain fixation throughout each trial (eye position was not monitored) and to use a chinrest to steady the head. They were then told that they would be viewing a large number of trials and that their task was to determine whether a line was drawn inward, toward the center of the display, or not. If they detected the line as being drawn toward the center of the display (the illusion), they were to press a button on the mouse marked "IN"; otherwise, they were to press the other mouse button. RTs and the observers' motion judgments were recorded.

Design. Three factors were systematically manipulated in this experiment: probe location (same or opposite to S1), ISI $(0,100$, $300,500$, or $900 \mathrm{msec})$, and target duration $(0,15,30$, or $45 \mathrm{msec}$ ). Trials lacking targets were analyzed separately from trials containing targets.

There was a total of 820 trials. The session began with a block of 20 practice trials. Data from practice trials were discarded. The 800 experimental trials were composed of 20 replications of each

\section{no target}

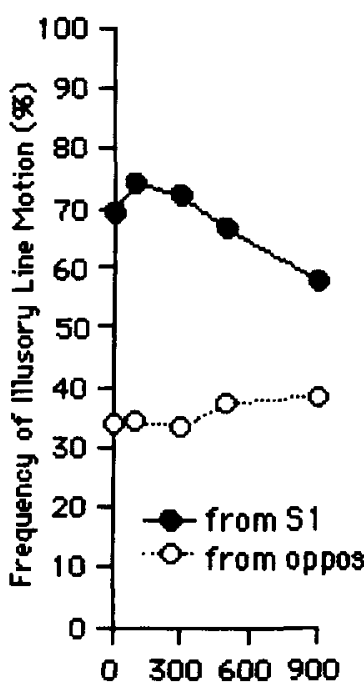

ISI
15 msec

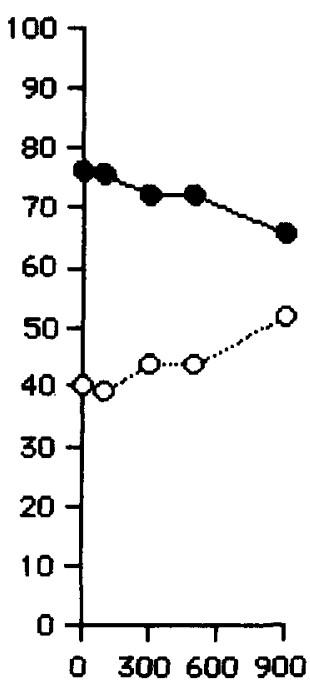

$|S|$
30 msec

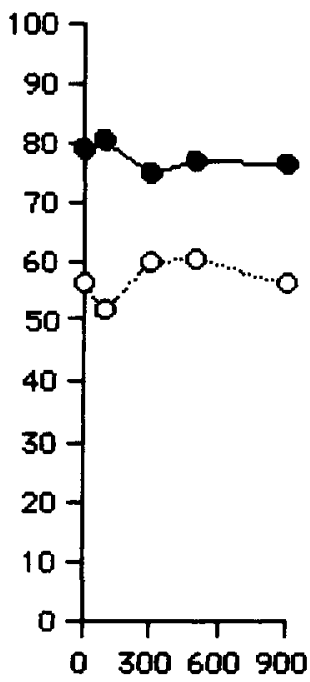

ISI
45 msec

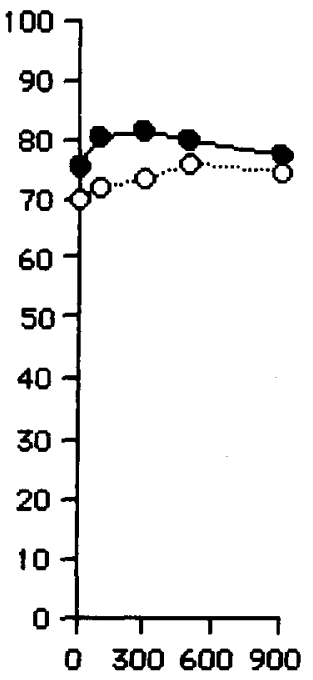

$|\mathbf{S}|$

Figure 2. Mean frequency of illusory line motion for all conditions in Experiment 1. Each panel represents one level of target duration, with the leftmost panel presenting the results when no target occurred before the probe line appeared. 
Table 1

Frequency of Line Motion Away From S1 and the Location Opposite S1, Along With Associate Planned Comparison Statistics (PCs) for All Levels of ISI in Experiment 1

\begin{tabular}{|c|c|c|c|c|c|c|}
\hline \multirow[b]{2}{*}{ ISI (msec) } & \multicolumn{3}{|c|}{ No Target } & \multicolumn{3}{|c|}{ Target Present } \\
\hline & $\begin{array}{c}\text { Same } \\
\text { Location (\%) }\end{array}$ & $\begin{array}{c}\text { Opposite } \\
\text { Location }(\%)\end{array}$ & $\begin{array}{c}\text { PCs } \\
F(1,36) \\
\end{array}$ & $\begin{array}{c}\text { Same } \\
\text { Location }(\%)\end{array}$ & $\begin{array}{c}\text { Opposite } \\
\text { Location (\%) }\end{array}$ & $\begin{array}{c}\mathrm{PCs} \\
F(1,72) \\
\end{array}$ \\
\hline 0 & 70 & 34 & $48.72^{*}$ & 77 & 56 & $95.23^{*}$ \\
\hline 100 & 74 & 34 & $60.32^{*}$ & 79 & 54 & $124.61 *$ \\
\hline 300 & 72 & 35 & $58.65^{*}$ & 76 & 59 & $60.62^{*}$ \\
\hline 500 & 67 & 37 & $32.92^{*}$ & 76 & 60 & $55.28^{*}$ \\
\hline 900 & 58 & 39 & $14.58^{*}$ & 73 & 61 & $31.52^{*}$ \\
\hline
\end{tabular}

${ }^{*} p<.001$.

possible combination of probe location, ISI, and target duration. Half of the replications positioned $S 1$ in the position to the left of the fixation; the other half positioned $S 1$ in the position to the right of fixation. The order of trial delivery was randomized separately for each observer.

\section{Results and Discussion}

For each condition, the primary analysis used the frequency of ILM as the dependent variable. Because the values for each probe location are derived from independent display presentations and judgments, these values should not be expected to summate to $100 \%$. The frequency that the subjects reported not getting ILM in each condition can be calculated from Figure 2. A discussion of the RT data is presented later, and RT analyses appear in the Appendix.

Frequency of line motion. The proportion of ILM reported away from S1 in each condition was calculated, and the data were analyzed using two separate analyses of variance (ANOVAs). One analysis was used to assess performance in conditions where there was no target, and the second was used to assess performance in conditions including a visible target before the probe line appeared.

The first analysis was a 2 (probe location) $\times 5$ (ISI) repeated measures ANOVA to assess conditions in which no target appeared before the probe line. Line motion was reported more frequently $[F(1,9)=14.25, p<.005]$ when the line probed the same location $(68 \%)$ as S1, compared with the opposite location (39\%). The ISI main effect failed to reach significance $[F(4,36)=1.26, p>$ .05]; however, there was a significant probe location $\times$ ISI interaction $[F(4,36)=2.72, p<.05]$. Interaction means are plotted in the leftmost panel of Figure 2 . Tests of simple effects of ISI at each level of location demonstrated that the source of this interaction was a decrease in line motion away from S1 with increasing ISI $[F(4,36)=$ $3.86, p<.05$; quadratic trend, $F(1,36)=6.44, p<.05]$ and no appreciable change in the location opposite $\mathrm{S} 1$ $[F(4,36)=0.49, p>.05]$. Therefore, significantly speeded perceptual processing occurred early in the time course and decayed significantly by $900 \mathrm{msec}$ after the removal of $\mathrm{S} 1$.

A set of planned comparisons contrasting the frequency of line motion when the line probed the same versus the opposite location revealed significantly more $(p<.001)$ line motion away from the same versus the opposite location at all levels of ISI (see Table 1). There- fore, these results do not support the notion that perceptual processing is inhibited at locations toward which observers have previously oriented. Surprisingly, even $900 \mathrm{msec}$ after the occurrence of the original stimulation, speeded, not delayed, perceptual processing is detected. Given that the simple effects statistics revealed a significant decline in speeded processing by $900 \mathrm{msec}$, it is arguable that no inhibition is present to counteract effects that prior orienting had on perception.

The remaining line motion data were analyzed with a 2 (probe location) $\times 5$ (ISI) $\times 3$ (target duration) repeated measures ANOVA. Cell means are plotted on the right side of Figure 2. A significant probe location $\times$ target duration interaction occurred $[F(2,18)=6.56, p<$ $.01]$. Tests of simple effects (see Table 2) of probe location at each level of target duration revealed that line motion occurred significantly more often $(p<.05)$ away from $\mathrm{S} 1$ when the target was presented there, in contrast to presenting the target at the location opposite $\mathrm{S} 1$ for the target duration of $15 \mathrm{msec}$, and marginally more often $(p<.10)$ for the target duration of $30 \mathrm{msec}$. Increasing the target duration resulted in an increased frequency of motion away from the target location independent of previous stimulation. This manipulation had the effect of increasing the time that the target led the probe, moving this duration toward the optimal range for producing the illusion $(100-150 \mathrm{msec})$. Consequently, greater levels of ILM occurred from both probe locations. At the shortest target durations, the illusion occurred more frequently when the target occupied the previously stimulated location, indicating that perceptual inhibition does not appear to be setting in with the additional stimulation supplied by a target.

A location $\times$ ISI interaction effect $[F(4,36)=2.91$, $p<.05]$ also supports the notion that there is no perceptual inhibition in the present paradigm. A set of planned

Table 2

Simple Effect Statistics and the Frequency of Line Motion in Each of the Stimulus Positions When the Target Was Present in Experiment 1

\begin{tabular}{cccc}
\hline $\begin{array}{c}\text { Target } \\
\text { Duration (msec) }\end{array}$ & $\begin{array}{c}\text { Same } \\
\text { Location }(\%)\end{array}$ & $\begin{array}{c}\text { Opposite } \\
\text { Location }(\%)\end{array}$ & $F(1,18)$ \\
\hline 15 & 72 & 44 & $7.69^{*}$ \\
30 & 78 & 57 & $3.76 \dagger$ \\
45 & 79 & 73 & 0.30 \\
\hline
\end{tabular}


comparisons revealed significantly more $(p<.0001)$ line motion away from the target when it appeared at the same versus the opposite location to $\mathrm{S} l$ at all levels of ISI (see Table 1). A main effect of location $[F(1,9)=9.72$, $p<.02]$ accompanied these interactions, showing that the illusion occurred more often overall at the same location as $S 1(76 \%)$ than at the opposite location $(58 \%)$. This is opposite to what would be expected if perception was inhibited in the present paradigm.

Finally, the notion that increasing the target duration resulted in an increase in line motion was supported by the main effect of target duration $[F(2,18)=14.11, p<$ $.0002]$ and the presence of a linear trend $[F(1,54)=$ $28.174, p<.0001]$. No other effects were found to be significant.

Response time data. For each observer, the mean RT for trials in each condition that fell in the range of 100 $1,500 \mathrm{msec}$ were analyzed. The exclusion of data outside this range is a common practice in IOR studies and resulted in the omission of less than $5 \%$ of the trials. The analyses applied to the illusion data were used to evaluate RT performance, and the results appear in the Appendix. It should be noted that, in this task, RTs reflect introspective experience rather than a speeded response to the appearance of the target or probe line. As a result, any conclusions drawn from RTs in this task are limited.

Planned comparison results contrasting probe location at each level of ISI appear in Table Al in the Appendix. Line judgments were always faster $(p<.05)$ when the location of $S 1$ was probed than when the location opposite $S 1$ was probed.

The results of Experiment 1 demonstrate that perceptual processing of a previously stimulated spatial location does not appear to be inhibited. Perceptions based on signals arising from previously stimulated locations also appear not to be inhibited. Observers are faster to make judgments based on perceptual processing at the previously stimulated location relative to judgments based on perceptual processing at the opposite location. These data support the notion that the RT inhibition observed in similar paradigms requiring a motor response may not be due to the inhibition of perceptual processing.

\section{EXPERIMENT 2}

Experiment 2 sought to replicate the basic findings of Experiment 1 with several improvements. In Experiment 1, participants may have been biased to report a high fre-

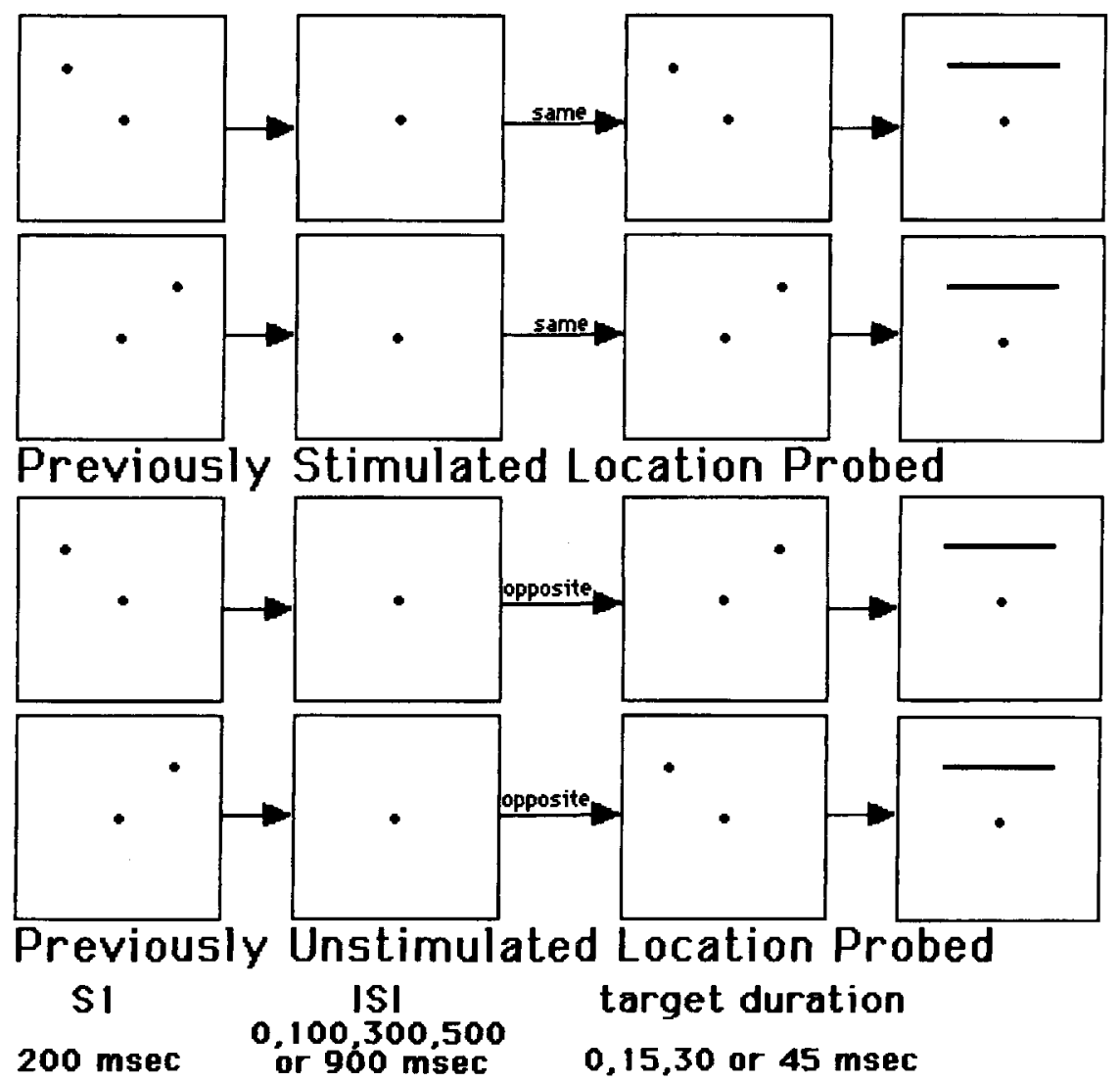

Figure 3. Experiment 2 trial sequence. Each trial began with a full field pattern for $1,000 \mathrm{msec}$, followed by the presentation of a fixation point for $800 \mathrm{msec}$. Next, S1 appeared for $200 \mathrm{msec}$ and was then extinguished for a variable ISI. In some conditions, the target appeared for a variable target duration, and then the probe line appeared between the two possible target locations. 
quency of line motion because they had no specific response option if they detected no motion versus if they detected motion away from the center of the display. Although the observers were instructed not to report such percepts as "IN" responses, they may have ignored instructions to so. Additionally, effects of the fovea may have interacted with illusory motion. Foveal signal transmission is faster than peripheral transmission and could therefore counteract ILM effects. Finally, presenting the probe line between the fixation point, which was always present, and the target location may have resulted in an exaggerated frequency of line motion toward the latter. Experiment 2 removed these potential contaminants by presenting a single line in the periphery between the two possible probe locations and by giving observers a wider range of response options.

In the present experiment's probe displays, a single horizontal line appeared connecting the two possible target positions. The observer responded to the probe display by classifying the line motion as coming from the left target position, having no motion, coming from the right target position, or motion toward the line's center coming from both of the possible target positions. On the basis of the position of the target and the observer's response, the location(s) of the display from which motion occurred were determined on each trial and were deemed to demonstrate speeded perceptual processing. The dependent measure in this experiment was the frequency that line motion was reported away from each of the possible display positions.

\section{Method \\ Observers. The same observers in Experiment 1 participated in Experiment 2.}

Apparatus and Stimuli. The apparatus and stimuli were identical to those of Experiment 1 except that the probe stimulus was a single line joining the two possible target positions.

Procedure. The procedure was identical to that of Experiment 1 except that, on each trial, the probe line appeared connecting the two possible target positions, and the observer classified the motion according to one of four possible categories.

Again, the experiment had two different types of trial, depending upon whether the target appeared at the same location as S1 or at the location opposite to S1. The sequence of events for each of the different trial types appears in Figure 3. Note that, in the notarget condition, the same versus the opposite conditions are phenomenologically identical; however, each assesses the frequency of facilitation relative to a different display position.

The observers made a judgment about the line motion by pressing a button on the computer mouse. The time to press the button was recorded, and a menu of four possible motion categories was presented: (1) LEFT, (2) NO MOTION, (3) RIGHT, and (4) BOTH. The observers were asked to enter, via the keyboard, the number corresponding to the location(s) of the origin of any perceived line motion in the display. That is, if the observers saw the line coming from the left or right, they entered 1 or 3 , respectively. If the observers saw the line being drawn from both ends and meeting in the middle, then they entered 4 . If the observers failed to perceive motion, they entered 2 . Entering a response initiated the sequence for the next trial. The observers were explicitly given the opportunity to take a break every 50 trials.

Design. The design was identical to that of Experiment 1.

\section{Results and Discussion}

Frequency of line motion. The proportion of trials in each condition that the observers reported line motion away from the (potential) target location was calculated and the data were analyzed as in Experiment 1.

Again, the first analysis was a 2 (probe location) $\times 5$ (ISI) repeated measures ANOVA to assess conditions in which no target appeared before the probe line. Speeded no target

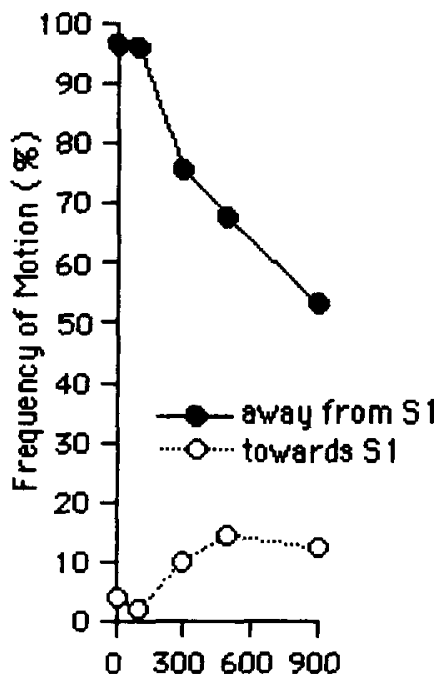

$|S|$
$15 \mathrm{msec}$

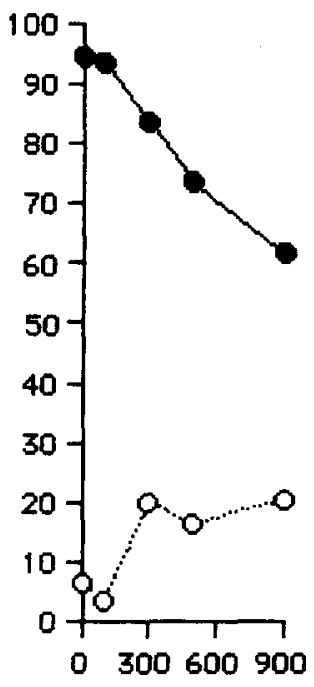

|S|
$30 \mathrm{msec}$

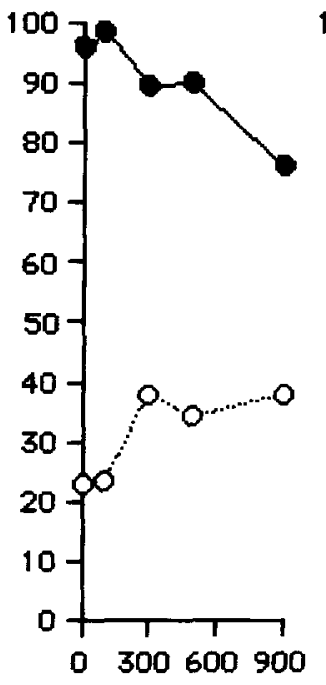

$|S|$
45 msec

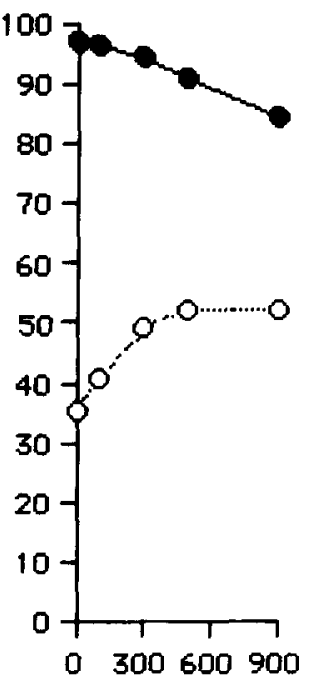

ISI

Figure 4. Mean frequency of reported facilitation for all conditions in Experiment 2. Each panel represents one level of target duration, with the leftmost panel presenting the results when no target occurred before the probe line appeared. 
Table 3

Frequency of Line Motion Away From S1 and the Location Opposite S1, Along With

Associate Planned Comparison Statistics (PCs) for All Levels of ISI in Experiment 2

\begin{tabular}{|c|c|c|c|c|c|c|}
\hline \multirow[b]{2}{*}{ ISI (msec) } & \multicolumn{3}{|c|}{ No Target } & \multicolumn{3}{|c|}{ Target Present } \\
\hline & $\begin{array}{c}\text { Same } \\
\text { Location }(\%)\end{array}$ & $\begin{array}{c}\text { Opposite } \\
\text { Location (\%) }\end{array}$ & $\begin{array}{c}\mathrm{PCs} \\
F(1,36)\end{array}$ & $\begin{array}{c}\text { Same } \\
\text { Location (\%) }\end{array}$ & $\begin{array}{c}\text { Opposite } \\
\text { Location (\%) }\end{array}$ & $\begin{array}{c}\text { PCs } \\
F(1,72) \\
\end{array}$ \\
\hline 0 & 97 & 4 & $286.91^{*}$ & 96 & 22 & $1069.88^{*}$ \\
\hline 100 & 96 & 2 & $295.98^{*}$ & 96 & 23 & $1055.50^{*}$ \\
\hline 300 & 76 & 10 & $143.86^{*}$ & 89 & 36 & $551.79^{*}$ \\
\hline 500 & 67 & 15 & $94.09 *$ & 85 & 34 & $498.97^{*}$ \\
\hline 900 & 53 & 12 & $55.66^{*}$ & 74 & 37 & $267.81 *$ \\
\hline
\end{tabular}

perceptual processing was indicated more frequently $[F(1,9)=168.59, p<.0001]$ at $\mathrm{S} 1(78 \%)$ than at the opposite location $(9 \%)$. The ISI main effect $[F(4,36)=6.74$, $p<.0005]$ reflected an overall decay in the speed of perceptual processing with increasing ISI. This effect was supported by a linear trend $[F(1,36)=25.19, p<.0001]$.

There was a significant probe location $\times$ ISI interaction $[F(4,36)=18.80, p<.0001]$. Interaction means are plotted in the leftmost panel of Figure 4. Tests of simple effects revealed that part of the source of this interaction was a decrease in line motion away from $\mathrm{S} 1$ with increasing ISI $[F(4,36)=15.6, p<.0001]$. This effect was supported by a significant linear trend $[F(1,36)=59.16, p<$ $.0001]$. Additionally, at the location opposite to $\mathrm{S} 1$, perceptual processing speed increased with ISI $[F(4,36)=$ $3.96, p>.01]$, and was also supported by a linear trend $[F(1,36)=11.62, p<.02]$. These data show both significant facilitation and decay by $900 \mathrm{msec}$ after the removal of S1.

Planned comparisons were used to contrast the frequency of line motion occurrence when the line probed the same versus the opposite location, revealing significantly more $(p<.0001)$ motion away from $\mathrm{S} 1$ versus the opposite location at all levels of ISI (see Table 3). The results of this analysis replicate the findings of Experiment 1 and add further support for the notion that perceptual processing is not inhibited by previous stimulation. Instead, an appreciable amount of facilitation at S1 existed, even $900 \mathrm{msec}$ after stimulation ceased.

The remaining motion data were analyzed with a 2 (probe location) $\times 5$ (ISI) $\times 3$ (target duration) repeated measures ANOVA. Cell means are plotted in the three rightmost panels of Figure 4. The major results of Experiment 1 were replicated. As before, a significant probe location $\times$ target duration interaction occurred $[F(2,18)=6.84, p<.006]$. Tests of simple effects (see Table 4) of probe location at each level of target duration revealed that motion occurred significantly more often $(p<.005)$ away from the location of $\mathrm{S} 1$ as opposed to away from the location opposite to $S 1$.

A location $\times$ ISI interaction effect $[F(4,36)=13.63$, $p<.0001]$ and associated planned comparisons revealed significantly more $(p<.0001)$ motion away from S1 when the target appeared there than when the target appeared at the location opposite S1, at all levels of ISI (see Table 3), supporting the notion that only facilitative effects were present at the perceptual level.

The main effect of location $[F(1,9)=51.28, p<.0001]$ reflected the high frequency of motion away from $\mathrm{S} 1$ (88\%) compared with motion away from the opposite location $(30 \%)$, and a main effect of target duration $[F(2,18)=$ $11.17, p<.001]$ reflected a linear increase in the speed of processing with increased target duration $[F(1,54)=$ 22.02, $p<.0002]$. No other effects were found to be significant.

A breakdown of the actual subject responses appears in Figure 5 for the no-target trials and in Figure 6 for the trials in which a target was present. These figures have been coded so that responses are relative to $\mathrm{S} 1$ instead of simply right versus left motion, as the observers reported. The frequency of report of each of the four response options for every experimental condition is shown. In the absence of a target (see Figure 5), it is clear that motion was judged to be predominantly away from S1. In trials containing a target (see Figure 6), it is apparent that the observers generally reported motion away from S1 and that a failure to perceive motion in the display occurred less frequently as the target duration increased. No motion was also reported most frequently at long ISIs, reflecting the decay of sped up processing with time. In the top half of Figure 6 are responses from trials in which the target appeared at $\mathrm{S} 1$, and in the bottom half of the figure are responses when the target appeared at the location opposite to S1. Even when a target appeared opposite $\mathrm{S} 1$, motion is generally away from $\mathrm{S} 1$, compatible with the notion that perceptual processing is facilitated by prior stimulation, not inhibited.

Response time data. The exclusion of RT data that fell in the range of $100-1,500$ msec resulted in the omis-

Table 4

Simple Effect Statistics and the Frequency of Facilitation in Each S1 Position When the Target

Was Present in Experiment 2

\begin{tabular}{cccc}
\hline $\begin{array}{c}\text { Target } \\
\text { Duration (msec) }\end{array}$ & $\begin{array}{c}\text { Same } \\
\text { Location (\%) }\end{array}$ & $\begin{array}{c}\text { Opposite } \\
\text { Location (\%) }\end{array}$ & $F(1,18)$ \\
\hline 15 & 81 & 13 & $154.39^{*}$ \\
30 & 90 & 31 & $40.68^{*}$ \\
45 & 93 & 46 & $13.61 \dagger$ \\
\hline
\end{tabular}

${ }^{*} p<.0001 . \quad{ }^{\dagger} p<.002$. 


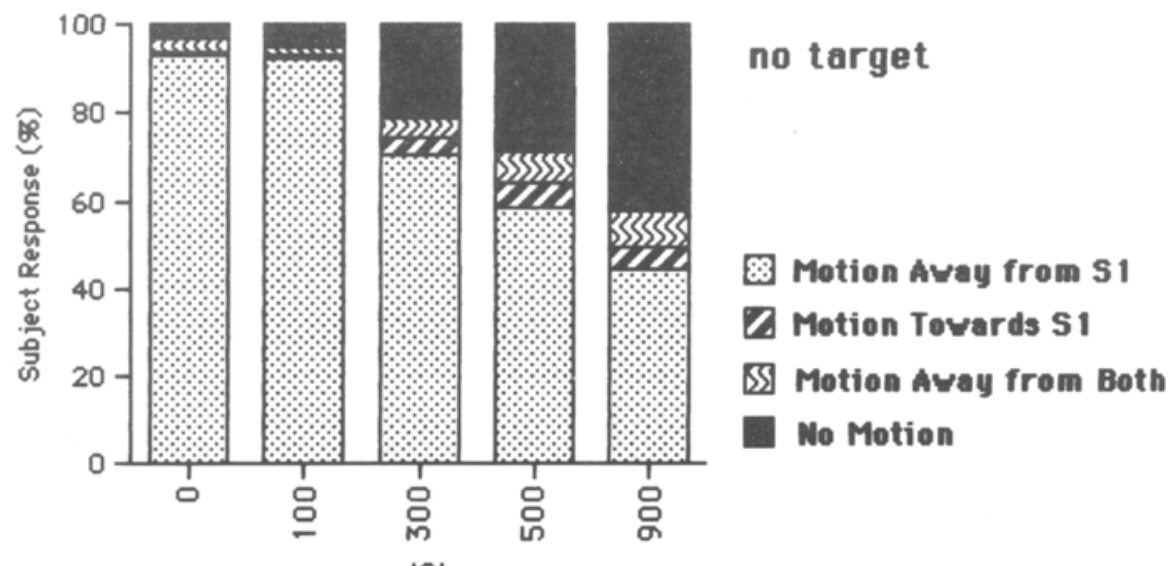

|S|

Figure 5. Breakdown of subject responses in each condition of Experiment 2 for trials lacking the presentation of a target.

sion of $14 \%$ of trials due principally to subjects' slow response initiation. Again, the results of RT analyses appear in the Appendix. Apparently, the perceptual task became more difficult as the time between S1 and the line probe increased. Planned comparisons contrasting probe location at each level of ISI revealed no significant effects.

Despite any differences in location with a judgment RT dependent measure, the data support the notion that the inhibition, or delay, of perceptual processing was not present in the present paradigm. Instead, the data from Experiments 1 and 2 suggest that only speeded perceptual processing occurs at previously stimulated spatial locations, even some time after stimulation has ceased. The failure to find inhibited RT in conjunction with the execution of a perceptual task is consistent with the interpretation that the RT delay is not due to a delay in perceptual processing, as the perceptual view of IOR suggests.

\section{EXPERIMENT 3}

Although the data from Experiments 1 and 2 suggest that the RT inhibition in standard IOR paradigms does not arise from the inhibition of perceptual representations, it could be argued that RT inhibition would not be present with similar timing and display parameters when a nonperceptual response is required. Therefore, Experiment 3 presented the target-present trials of Experiments 1 and 2 , and required that the subjects execute a simple RT detection task. The probe line was not displayed, and the subjects simply responded to the target. The target was visible for the same duration as in the previous experiments $(15,30$, or $45 \mathrm{msec})$.

Experiment 3 implemented the standard IOR paradigm. Therefore, if IOR is present with a manual detection response under the same conditions as those in Experiments 1 and 2, then the RT inhibition in IOR does not reflect an inhibition of perception but is probably an effect of the visual-motor system.

\section{Method}

Observers. The same observers in Experiments 1 and 2 participated in Experiment 3.

Apparatus and Stimuli. The apparatus and stimuli were identical to those of Experiment 1 except that the probe line stimulus was abandoned.

Procedure. The procedure was identical to that of Experiment 1 except that the observers were not making perceptual judgments of motion but were instead performing a simple detection task.

The sequence of events for each of the different trial types appears in Figure 7 . Each trial began with the appearance of a full field pattern for $1,000 \mathrm{msec}$ followed by a lone fixation point for $800 \mathrm{msec}$. Sl appeared for $200 \mathrm{msec}$ and was then extinguished for a variable ISI $(100,300,500$, or $900 \mathrm{msec})$. Next, the target stimulus, which was identical to $S 1$, appeared for a variable target duration $(15,30$, or $45 \mathrm{msec})$.

The observer was instructed to press the left button on a computer mouse as quickly as possible after the appearance of the target. The time to press the button was recorded, accurate to the nearest millisecond.

Design. As in the previous experiments, three factors were systematically manipulated: probe location (same or opposite to $\mathrm{S} 1$ ), ISI $(100,300,500$, or $900 \mathrm{msec})$, and target duration $(15,30$, or $45 \mathrm{msec})$.

There was a total of 500 trials. The session began with a block of 20 practice trials. Data from practice trials were discarded. The 480 experimental trials were composed of 20 replications of each possible combination of probe location, ISI, and target duration. Half of the replications positioned $\mathrm{S} 1$ in the position to the left of the fixation, and the other half positioned $S 1$ in the position to the right of fixation. The order of trial delivery was randomized separately for each observer.

\section{Results and Discussion}

The mean RTs for trials in each condition that fell in the range of $100-1,500 \mathrm{msec}$ were analyzed with a 2 (probe location) $\times 4$ (ISI) $\times 3$ (target duration) repeated measures ANOVA. Less than 3\% of the RT data were omitted. Cell means are plotted in Figure 8.

As in Experiment 1, target duration interacted with the probe location $[F(2,18)=3.96, p<.05]$. However, in contrast to Experiments 1 and 2, the observers were slower to respond to the target at all levels of target du- 


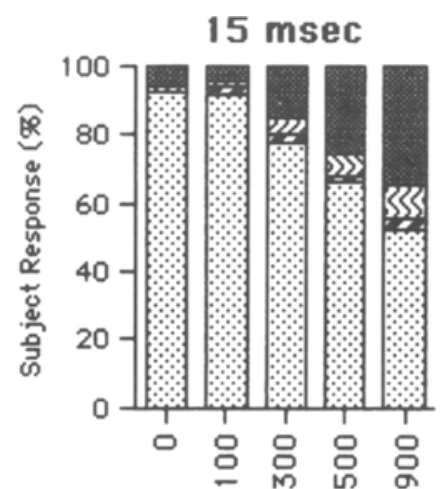

IS|

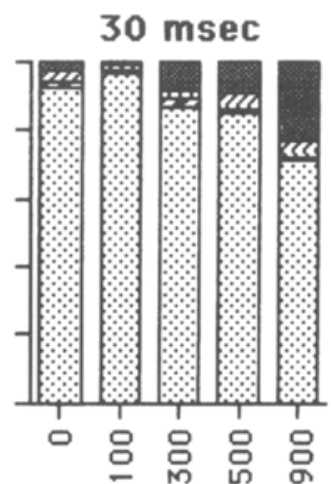

IS|

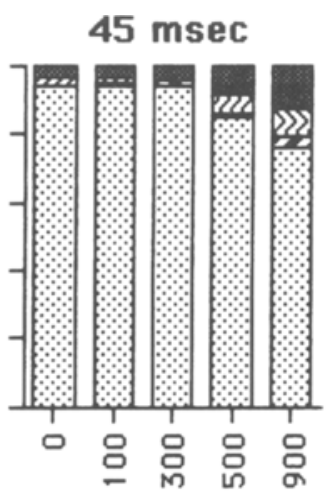

IS|

\section{Target at S1}

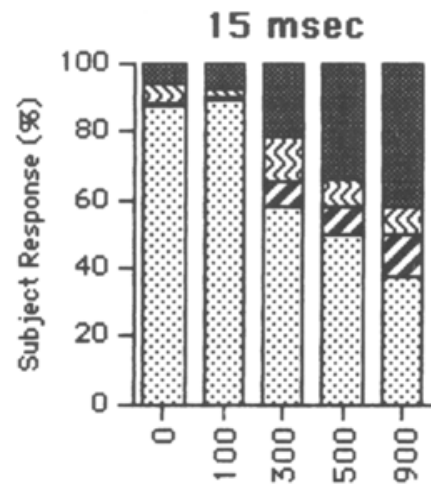

IS|

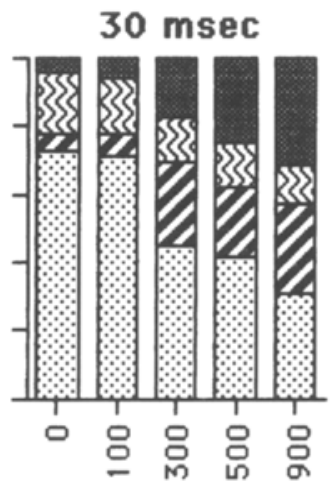

IS|

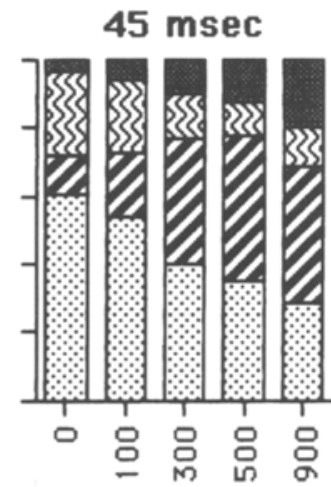

IS|

\section{Target opposite S1}

\section{Motion Away from S1}

Motion Tovards S1

\section{B] Motion Avay from Both}

Mo Motion

Figure 6. Breakdown of subject responses in each condition of Experiment 2 with targets present. The top half of the figure presents the frequency of observers' responses when the target appeared at the same location as $\mathrm{S1}$; the bottom half of the figure presents responses to the target appearing at the location opposite $S 1$.

ration. Despite 70-, 63-, and 36-msec RT differences to the target locations for $15-, 30-$, and $45-\mathrm{msec}$ target durations, the simple effects of location at each level of target duration failed to reach significance due to a lack of power (all $p \mathrm{~s}<.15$ ).

Probe location also interacted with $\operatorname{ISI}[F(3,27)=8.33$, $p<.009]$. A set of planned comparisons revealed that at every level of ISI, the observers were significantly slower to respond to the target if it appeared at the location of S1 than if it appeared at the previously unstimulated location (see Table A2 in the Appendix). Therefore, IOR is present using the display and timing parameters from Experiments 1 and 2 when a simple detection task, rather than a perceptually based task, is used. It should be noted that the present experiments sampled only a time course in which inhibition would be expected-making them insensitive to the early facilitative component that often accompanies IOR.

A significant interaction $[F(6,54)=4.03, p<.05]$ between target duration and ISI apparently resulted from longer RTs to targets at the smallest levels of ISI (100 and

Table 5

RTs and Associated Planned Comparison Statistics (PCs) at All Levels of ISI From Experiment 3

\begin{tabular}{cccc}
\hline ISI $(\mathrm{msec})$ & $\begin{array}{c}\text { Same } \\
\text { Location }\end{array}$ & $\begin{array}{c}\text { Opposite } \\
\text { Location }\end{array}$ & $\begin{array}{c}\text { PCs } \\
F(1,54)\end{array}$ \\
\hline 100 & 524 & 415 & $76.39^{*}$ \\
300 & 405 & 357 & $14.64^{*}$ \\
500 & 370 & 331 & $9.95^{*}$ \\
900 & 368 & 339 & $5.38 \dagger$ \\
\hline${ }^{*} p<.005 .{ }^{\dagger} p<.03$. & &
\end{tabular}




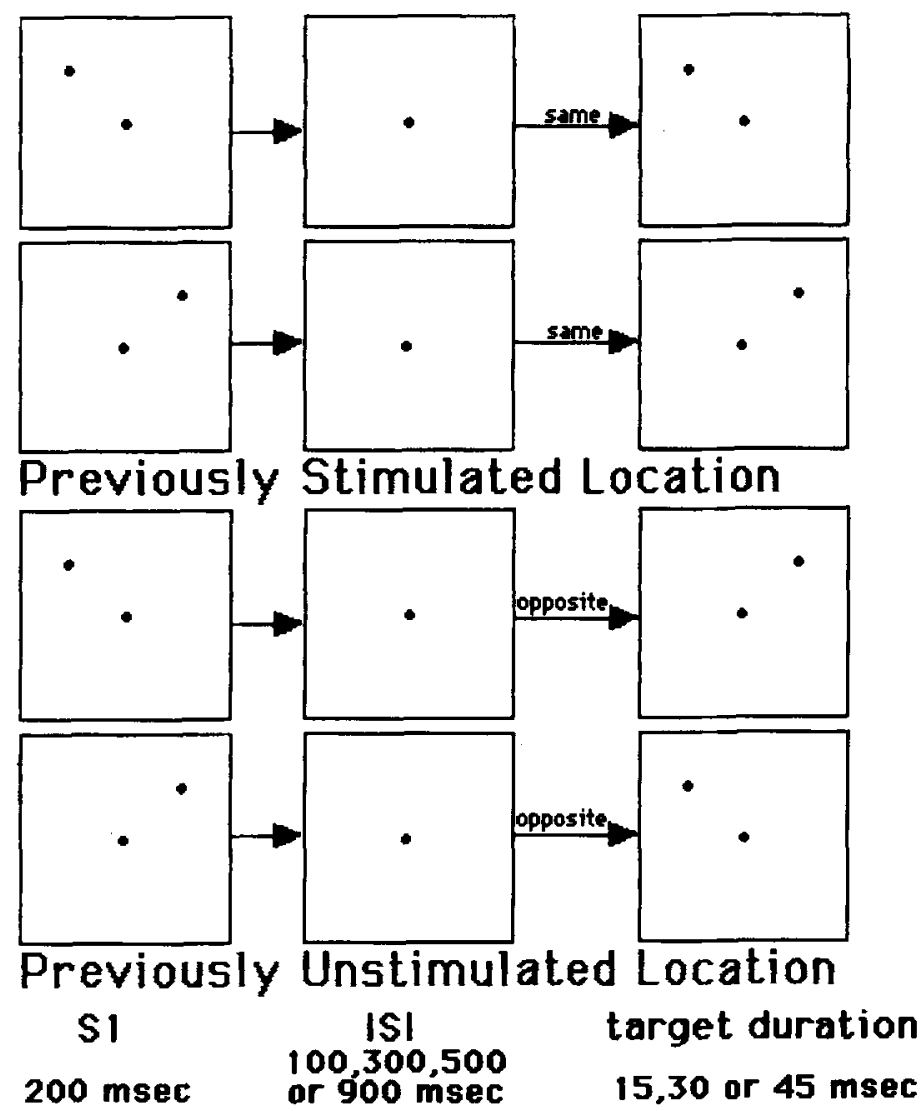

Figure 7. Experiment 3 trial sequence. Each trial began with a full field pattern for $1,000 \mathrm{msec}$, followed by the presentation of a fixation point for 800 msec. Next, S1 appeared for 200 msec and was then extinguished for a variable ISI, followed by a target for a variable target duration.

$300 \mathrm{msec})$ with the shortest target duration (15 msec). The simple effects of target duration at all levels of ISI were not significant. Although the interaction may have resulted from forward masking of the target by S1, the short target presentation time is a more probable cause of the interaction, since target duration and ISI failed to interact with probe location. Forward masking may have played some role at the smallest levels of ISI, since S1 and the target were identical in this experiment (to act as an appropriate control for Experiments 1 and 2). In conventional IOR paradigms, SI and the target are distinguishable to limit the effects of forward masking.

The ISI main effect $[F(3,27)=23.52, p<.0002]$ showed that the observers' RTs decreased linearly $[F(1,54)=15.95, p<.005]$ as ISI increased, a common effect in RT studies (Niemi \& Näätänen, 1981). A location main effect was the only other significant effect $[F(1,9)$ $=64.62, p<.0001]$, adding support to the notion that IOR occurred under the present display and timing parameters.

\section{GENERAL DISCUSSION}

The present set of experiments has demonstrated that, in a standard IOR paradigm, RT inhibition is present at previously stimulated target locations if a simple manual response is required of subjects; however, no inhibition is present when the task requires that subjects respond on the basis of perceptual qualities of the stimulus. Experiments 1 and 2 added support for the notion that perceptual representations are not inhibited by IOR by showing that, under identical display and timing parameters in which RT inhibition is observed with a simple manual response (Experiment 3), the use of a separate dependent measure based on perceptual qualities of the stimulus revealed no evidence for inhibited perceptual processing. On the contrary, perceptual processing speed was enhanced at precisely the spatial locations that the perceptual view of IOR assumes are the source of the RT delay. Even $900 \mathrm{msec}$ after previous stimulation, the location where S1 had appeared demonstrated a facilitative advantage over the opposite display location.

Some concern has been raised that the perceptual measure used in the present study is not attention-sensitive (Downing \& Treisman, 1995); however, there are few data demonstrating this, while numerous data require the postulation of an attentional component to ILM (see Schmidt \& Klein, 1996). In addition, no alternative to the gradient explanation has been proposed that is capable of 
$15 \mathrm{msec}$

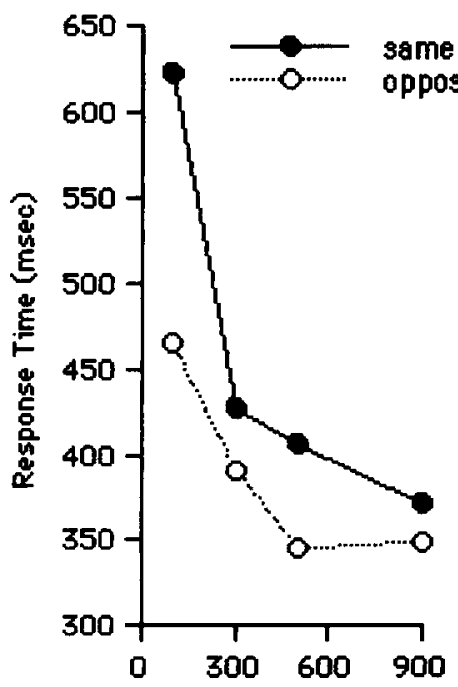

|S|
30 msec

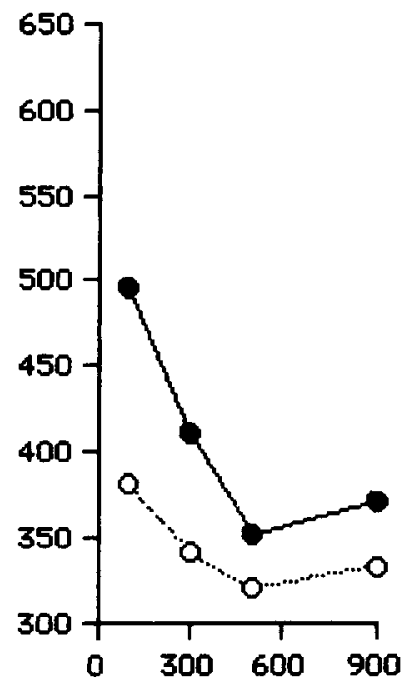

$|S|$
45 msec

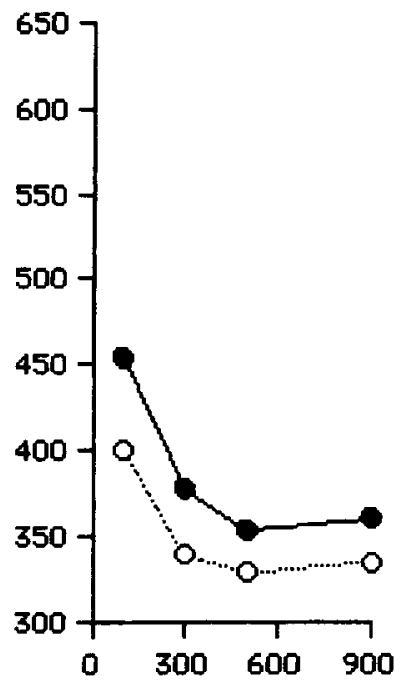

|SI

Figure 8. Mean detection RT for all conditions in Experiment 3. Each panel represents one level of target duration.

accommodating as many ILM findings. Should evidence emerge that ILM is not attention-sensitive, then the conclusions obtained from the present experiments are restricted to perceptual representations that are not influenced by attention, but that do affect ILM. However, as our present knowledge of ILM stands, the conclusions obtained apply to perceptual representations that can be affected by exogenous attentional manipulations.

Recently, researchers have claimed to observe inhibitory RT components whose sources are both sensory and attentional. Tassinari and Berlucchi (1993) proposed that a short-term sensory component and a longer lasting component dependent upon prior orienting are jointly involved in producing RT inhibition. Abrams and Dobkin (1994) suggested that their eye-movement data provided evidence for separately inhibited detection and motor processes. However, both of these studies used RT as the sole dependent measure. In doing so, they assumed that the RT data generated by simple motor responses reflected the inhibition of perceptual processing. Without supplementary evidence regarding the source of the delay in processing, there is little reason to expect that the inhibitory RT components observed were caused by inhibited perceptual processing as opposed to inhibited responding, inhibited visual-motor system processing, or a myriad of other potential sources.

A number of research findings run counter to the perceptual explanation of IOR. As mentioned earlier, Klein (1988) reasoned that an attentional inhibitory mechanism that prevents the reinspection of information at previously examined locations could serve to improve visual search efficiency. Although Klein (1988) originally found support for this functional notion of IOR, further attempts to replicate from Klein's own lab (see Klein \& Taylor, 1994) and others' (Wolfe \& Pokorny, 1990) have failed. Attention does not seem to be inhibited from returning to previously examined locations in visual search, making these results inconsistent with the view that IOR reflects an inhibition of perceptual processing at previously examined locations. Note that this does not mean that subjects do not use some other means to prevent the redundant processing of already-processed display items.

Recently, a number of studies have reported failures to observe IOR in discrimination tasks in which the observer's response is based on perceptual features of the stimulus. Klein and Taylor (1994) report unpublished results by Pontefract and Klein (1988) demonstrating a failure to observe IOR in tasks that require subjects to make a discrimination response that is based on a stimulus attribute other than location (size). Although the stimuli used in separate experiments were identical, IOR was observed only in cases where a simple detection response task (press a button as quickly as possible once the second stimulus appears) was used. In experiments requiring that subjects make a perceptual discrimination (i.e., press one button if a circle expanded and a different button if a circle contracted), RT was facilitated rather than inhibited when the discrimination involved perceptual aspects of $\mathrm{S} 1$.

Apparently, whenever a localization response is required, IOR is present. In keeping with this conclusion, Maylor (1985; Pratt, 1995) found IOR in discrimination experiments in which a localization response (eye movement to the target location, and a buttonpress that was spatially compatible with the target location) was required. Terry, Valdes, and Neill (1994), Egly, Rafal, and 
Henik (1992), and Kingstone and Gazzaniga (1992) also reported a consistent same-location advantage in the IOR paradigm when a target discrimination, based on perceptual qualities of the stimulus (i.e., press one button if quality $x$ is present, and another button if quality $y$ is present), was required, but not when a simple detection or spatially compatible location discrimination response was involved. This pattern of results does not fit with the idea that perceptual processing of these stimuli was inhibited, as is suggested by the perceptual view of IOR. ${ }^{2}$

An additional set of IOR experiments by Tanaka and Shimojo (1993, 1994) varied subjects' task requirements using identical stimuli in each task. In some experiments, subjects were asked to discriminate the color, orientation, or shapes of the objects involved, whereas, in other experiments, the task was to simply detect the target object's appearance or to make a location discrimination response. As in the studies reported above, tasks requiring the localization of the target showed inhibited RT effects, whereas tasks requiring object identification or judgments about the object's perceptual attributes were facilitated. More recently (Tanaka \& Shimojo, 1995), these researchers have reported that while repetition across a number of trials results in increased facilitation in discrimination tasks based on perceptual qualities of the stimulus, there is no such facilitative advantage for location repetition. Instead, as is usually found in IOR paradigms, location repetition increased the magnitude of the inhibitory response (Maylor \& Hockey, 1987). Again, these results suggest qualitatively different, task-dependent processing of location and feature.

Tanaka and Shimojo (1994) interpreted their findings in terms of recent neurobiological theories of visual processing that propose separable neural pathways for action and cognition. Tasks simply requiring target localization could be carried out by the "where" visual pathway, whereas the "what" visual pathway could be responsible for handling tasks requiring elaborative perceptual and cognitive processing (Goodale \& Milner, 1992; Ungerleider \& Mishkin, 1982). Under this explanation, whenever the experimental task requires that subjects simply locate the target in order to make a response, the visual-motor action system is the quickest to initiate a response. However, when the task requires discriminations or other sorts of elaborative processing based on stimulus attributes, the visual-perception system is required and the response is initiated after cognitive processing has taken place. The action system may also be processing the stimulus while elaborative processing is occurring; however, because the action system is hypothesized not to be the initiator of the response, IOR is not observed, but instead RT facilitative effects, which are generally associated with attentional cuing, are observed. The inhibition in IOR is hypothesized to arise from the visual-motor action pathway, whereas attentional cuing effects are attributable to the cognitive visual-perception system.

To further test the two visual systems explanation, Tanaka and Shimojo carried out a supplementary set of
IOR style experiments: one requiring a reaching response, and the other requiring a vernier acuity discrimination. They expected to observe IOR only in the reaching task. Their results, which present difficulties for the perceptual view of IOR, supported the two-visual-systems explanation. The present data also support such an explanation, not only in that they dissociate results based upon whether the experimental task involves perception or action systems but also because of further evidence that ILM processing predominantly takes place in the visual-perception system (Steinman, Steinman, \& Lehmkuhle, 1994).

There is independent support for the notion that the origins of IOR lie in the visual-motor system. Rafal, Calabresi, Brennan, and Sciolto (1989) have proposed that saccadic programming is responsible for the RT inhibition present in the IOR paradigm. That is, once a saccade has been prepared to a spatial location, the system is inhibited from preparing a subsequent saccade to that location. When Rafal et al. instructed subjects to prepare or execute saccades to spatial locations (endogenous cuing), RT inhibition was observed. IOR was not observed, however, in the absence of external stimulation (peripheral cuing) or explicit instructions to prepare to look at the cued location. That is, when subjects' attention was cued with a simple arrow (central cuing) and when they had not been instructed to prepare to look at the location, no RT inhibition resulted (Posner \& Cohen, 1984; Rafal et al., 1989). In the typical IOR paradigm, peripheral cuing methods are used. Peripheral cuing is believed to automatically activate saccadic programming (Posner, 1980; Posner \& Cohen, 1980), whereas central cuing does not (Klein, 1980; Klein \& Pontefract, 1994). This suggests that preparing a saccade to a spatial location is a sufficient condition for causing IOR, whereas simply attending to a spatial location is not.

Further support for the notion that saccadic programming is involved in the generation of IOR comes from some recent results suggesting that IOR can be observed in the auditory modality (Schmidt, 1993; Ward, 1994). Schmidt (in press) found that even in the absence of visual input, subjects who were instructed to prepare saccades to an auditory location were slower to respond to an auditory target presented at that location than to an auditory target presented at a different location. Thus, IOR can occur even in the absence of visual stimulation, providing further evidence that representations subserving visual perception need not be inhibited for IOR to occur. Saccadic programming to auditory or visual spatial locations may result in the inhibition of the same overt orienting mechanism.

The saccadic programming hypothesis supplements the two-visual-systems explanation because saccadic programming is believed to be occurring in the visualmotor pathway, which was discussed earlier as the origin of the IOR effect. Saccadic programs are believed to be computed by the superior colliculus, a brain center that participates in making responses to specific visual locations. Converging evidence that the visual-motor system 
is the source of IOR comes from a number of studies implicating the superior colliculus in IOR generation (Posner et al., 1985; see Schmidt, in press, for an overview).

Given that little direct evidence exists that IOR acts on perceptual representations - yet that a wealth of evidence exists suggesting that IOR acts on visual-motor representations-its role and origin in the latter should be a starting-off point for future research on the phenomenon. If IOR results from saccade preparation (Rafal et al., 1989), then a link between such overt orienting and manual movements might exist. It is possible, for instance, that reaching toward a target is accompanied by a previously prepared saccade that anchors the target's spatial location. Perhaps multiple locations can be anchored in the same manner (Tipper, Weaver, \& Watson, in press; but see Abrams \& Pratt, in press, and Pratt \& Abrams, in press).

The results of the present report may stimulate the rethinking of the theoretical organization of the results of a number of studies that have treated the perceptual view of IOR as foundational and may prevent researchers from assuming that IOR is acting in paradigms in which it may not be.

\section{REFERENCES}

ABRAMS, R. A., \& Dobkin, R. S. (1994). Inhibition of return: Effects of attentional cueing on eye movement latencies. Journal of Experimental Psychology: Human Perception \& Performance, 20, 467-477.

Abrams, R. A., \& Pratt, J. (in press). Spatially-diffuse inhibition affects multiple locations: A reply to Tipper, Weaver, and Watson (1996). Journal of Experimental Psychology: Human Perception \& Performance.

Downing, P., \& Treisman, A. (1995). The shooting line illusion: Attention or apparent motion? Investigative Ophthalmology \& Visual Science, 36, S856.

Downing, P., \& Treisman, A. (in press). The line-motion illusion: Attention or impletion? Journal of Experimental Psychology: Human Perception \& Performance.

Egly, R., Rafal, R. D., \& Henik, A. V. (1992, November). Reflexive and voluntary orienting in detection and discrimination tasks. Paper presented at the 33rd Annual Meeting of the Psychonomic Society, St. Louis.

FINLEY, G. (1985). A high-speed point plotter for vision research. $V i$ sion Research, 25, 1993-1997.

GiBSON, B. S., \& EGETH, H. (1994). Inhibition and disinhibition of return: Evidence from temporal order judgments. Perception \& Psychophysics, 56, 669-680.

Goodale, M. A., \& Milner, A. D. (1992). Separate visual pathways for perception and action. Trends in Neurosciences, 15, 20-25.

Hikosaka, O., Mryauchi, S., \& Shimojo, S. (1991). Focal visual attention produces motion sensation in lines. Investigative Ophthalmology \& Visual Science, 32, 716.

Hikosaka, O., Miyauchi, S., \& Shimojo, S. (1993a). Focal visual attention produces illusory temporal order and motion sensation. $V i$ sion Research, 33, 1219-1240.

Hikosaka, O., Miyauchi, S., \& Shimojo, S. (1993b). Visual attention revealed by an illusion motion. Neuroscience Research, 18, 11-18.

HikosaKa, O., Miyauchi, S., \& Shimojo, S. (1993c). Voluntary and stimulus-induced attention detected as motion sensation. Perception, 22, 517-526.

Houghton, G., \& TipPER, S. P. (1994). A model of inhibitory mechanisms in selective attention. In D. Dagenbach \& T. H. Carr (Eds.), Inhibitory mechanisms in attention, memory and language (pp. 53112). New York: Academic Press.

Kingstone, A., \& GazZaniga, M. S. (1992, June). Covert orienting in the split brain. Paper presented at the Canadian Society of Brain, Behaviour, and Cognitive Science, Quebec City.

KLEIN, R. M. (1980). Does oculomotor readiness mediate cognitive control of visual attention? In R. S. Nickerson (Ed.), Attention and performance VIII (pp. 259-276). Hillsdale, NJ: Erlbaum.

KLEIN, R. M. (1988). Inhibitory tagging system facilitates visual search. Nature, 334, 430-431.

Klein, R. M., \& Pontefract, A. (1994). Does oculomotor readiness mediate cognitive control of visual attention? Revisited! In C. Umiltà \& M. Moscovitch (Eds.), Attention and performance $X V$ : Conscious and nonconscious processes (pp. 333-350). Hillsdale, NJ: Erlbaum.

KLEIN, R. M., \& TAYLOR, T. L. (1994). Categories of cognitive inhibition with reference to attention. In D. Dagenbach \& T. H. Carr (Eds.), Inhibitory mechanisms in attention, memory and language (pp. 113-150). New York: Academic Press.

KWAK, H.-W., \& EGETH, H. (1992). Consequences of allocating attention to locations and to other attributes. Perception \& Psychophysics, 51, 455-464.

Law, M. B., Pratt, J., \& Abrams, R. A. (1995). Color-based inhibition of return. Perception \& Psychophysics, 57, 402-408.

MAYLOR, E. A. (1985). Facilitatory and inhibitory components of orienting in visual space. In M. I. Posner \& O. S. M. Marin (Eds.), Mechanisms of attention: Attention and performance XI (pp. 189204). Hillsdale, NJ: Erlbaum.

MAYLOR, E. A., \& HoCKEY, R. (1987). Effects of repetition on the facilitatory and inhibitory components of orienting in visual space. Neuropsychologia, 25, 41-54.

MiYauchi, S., HikosaKa, O., \& Shimojo, S. (1992). Visual attention field can be assessed by illusory line motion sensation. Investigative Ophthalmology \& Visual Science, 33, 1262.

Niemi, P., \& NäÄTÄNEN, R. (1981). Foreperiod and simple reaction time. Psychological Bulletin, 89, 133-162.

Pontefract, A., \& Kiein, R. M. (1988). Assessing inhibition of return with simple and choice reaction time. Unpublished manuscript.

POSNER, M. I. (1980). Orienting of attention. Quarterly Journal of Experimental Psychology, 32, 3-25.

Posner, M. I., \& Cohen, Y. (1980). Attention and the control of movements. In G. E. Stelmach \& J. Requin (Eds.), Tutorials in motor behaviour (pp. 243-258). Amsterdam: North-Holland.

Posner, M. I., \& CoHen, Y. (1984). Components of visual orienting. In H. Bouma \& D. Bowhuis (Eds.), Attention and performance $X$ (pp. 531-556). Hillsdale, NJ: Erlbaum.

Posner, M. I., Rafal, R. D., Choate, L. S., \& Vaughan, J. (1985). Inhibition of return: Neural basis and function. Cognitive Neuropsychology, 2, 211-228.

Pratr, J. (1995). Inhibition of return in a discrimination task. Psychonomic Bulletin \& Review, 2, 117-120.

Pratt, J., \& Abrams, R. A. (in press). Inhibition of return to successively cued spatial locations. Journal of Experimental Psychology: Human Perception \& Performance.

Pylyshyn, Z. W. (1984). Computation and cognition: Toward a foundation for cognitive science. Cambridge, MA: MIT Press.

Rafal, R. D., Calabresi, P. A., Brennan, C. W., \& Sciolto, T. K. (1989). Saccade preparation inhibits reorienting to recently attended locations. Journal of Experimental Psychology: Human Perception \& Performance, 15, 673-685.

SchmidT, W. C. (1993). Auditory inhibition of return. Unpublished manuscript.

Schмid, W. C. (in press). "Inhibition of return" without visual input. Neuropsychologia.

Schmidt, W. C., Fisher, B. D., \& Pylyshyn, Z. W. (1996). Multiple onset stimuli elicit illusory line motion. Manuscript submitted for publication.

Schmidt, W. C., \& Klein, R. M. (1996). Gradients, impletion, and attention in illusory line-motion. Investigative Ophthalmology \& Visual Science, 37, S529.

Schmidt, W. C., Klein, R. M., \& Müller, H. J. (1996). Temporal order judgments do not reveal "inhibition of return": A commentary on Gibson and Egeth (1994). Manuscript submitted for publication. 
Steinman, B. A., Steinman, S. B., \& Lehmkuhle, S. (1994). Line motion illusion reveals that focal visual attention is dominated by the M-stream. Investigative Ophthalmology \& Visual Science, 35, 1622.

Stelmach, L. B., \& Herdman, C. M. (1991). Directed attention and perception of temporal order. Journal of Experimental Psychology: Human Perception \& Performance, 17, 539-550.

Sternberg, S., \& KNOLl, R. L. (1973). The perception of temporal order: Fundamental issues and a general model. In S. Kornblum (Ed.), Attention and performance IV (pp. 629-685). New York: Academic Press.

TANAKA, Y., \& Shimojo, S. (1993). Location priming and probability priming are isolatable in detection and discrimination. Investigative Ophthalmology \& Visual Science, 34, 1234.

TANAKA, Y., \& Shimojo, S. (1994). Location vs. feature: Two visual functions separated by reaction time in the pop out display. Investigative Ophthalmology \& Visual Science, 35, 1619.

TANAKa, Y., \& Shimojo, S. (1995). Facilitation induced by color and shape repetition but not by location repetition. Investigative Ophthalmology \& Visual Science, 36, S902.

TASSINARI, G., \& BERLUCCHI, G. (1993). Sensory and attentional components of slowing of manual reaction time to non-fixated visual targets by ipsilateral primes. Vision Research, 33, 1525-1534.

Terry, K. M., Valdes, L. A., \& Neill, W. T. (1994). Does "inhibition of return" occur in discrimination tasks? Perception \& Psychophysics, 55, 279-286.

Tipper, S., Weaver, B., \& Watson, F. (in press). Inhibition of return to successively cued spatial locations: A commentary on Pratt and Abrams (1996). Journal of Experimental Psychology: Human Perception \& Performance.

TownsEnd, J. T. (1992). On the proper scales for reaction time. In H.-G. Geissler, S. W. Link, \& J. T. Townsend (Eds.), Cognition, information processing, and psychophysics: Basic issues (pp. 105120). Hillsdale, NJ: Erlbaum.

Tsotsos, J. K. (1993). An inhibitory beam for attentional selection. In L. Harris \& M. Jenkin (Eds.), Spatial vision for humans and robots (pp. 313-331). Cambridge: Cambridge University Press.

UNGERLEIDER, L. G., \& MishKIN, M. (1982). Two cortical visual systems. In D. J. G. Ingle \& J. W. Mansfield (Eds.), Analysis of visual behavior (pp. 549-586). Cambridge, MA: MIT Press.

WARD, L. M. (1994). Supramodal and modality-specific mechanisms for stimulus-driven shifts of auditory and visual attention. Canadian Journal of Experimental Psychology, 48, 242-259.

Wolfe, J. M., \& PoKorny, C. W. (1990). Inhibitory tagging in visual search: A failure to replicate. Perception \& Psychophysics, 48, 357-362.

YANTIS, S., \& JoNEs, E. (1991). Mechanisms of attentional selection: Temporally modulated priority tags. Perception \& Psychophysics, 50, 166-178.

\section{NOTES}

1. Recently, Gibson and Egeth (1994) used a speeded TOJ task to investigate whether IOR is a perceptual affect. On the assumption that IOR modulates visual perception, coupled with the invention of a new process called disinhibition of return (which prevents IOR from affecting perception), Gibson and Egeth concluded that IOR affects TOJs. However, Schmidt, Klein, and Müller (1996) have noted that
Gibson and Egeth's accuracy data replicated previous TOJ work and that only in RT was an effect of IOR present. The Gibson and Egeth dissociation between RT and TOJ measures fits nicely into the framework presented in the General Discussion section.

2 . One anomalous finding to this collection of IOR results comes from Law, Pratt, and Abrams (1995). These researchers used a paradigm that departed markedly (both in its spatial layout and in the time course of stimulus presentation) from that characteristic of IOR studies. They presented color "cues" and targets successively at a single spatial location on every trial. Using this method, they found that subjects were slower to respond to the target color when it had been preceded by a same-colored patch than when it had been preceded by an opposite-colored patch. These researchers concluded that IOR was responsible for their finding. It is difficult to know, however, whether the same or a similar mechanism underlies this finding and results using the conventional paradigm, especially in light of Kwak and Egeth's (1992) failure to observe IOR with color-based stimuli using conventional methods. Further research into the mechanism of this color-based effect are required.

\section{APPENDIX RT Analyses}

\section{Experiment 1}

A 2 (probe location) $\times 5$ (ISI) repeated measures ANOVA for trials without a target revealed only a main effect of ISI $[F(4,36)=3.15, p<.03]$ supported by a linear trend $[F(1,36)=$ $10.70, p<.0001]$ of decreasing RT with increasing ISI.

The main effect of location $[F(1,9)=4.45, p<.07]$ approached significance. A set of planned comparisons (see Table A1) revealed that, at every level of ISI, RT to make motion judgments was faster when the line probed the location of $\mathrm{S} 1$ than when the line probed the location opposite S1. However, only with ISIs less than $300 \mathrm{msec}$ can this difference be considered significant. No other effects were found to be significant.

The remaining RT data for trials with targets present were analyzed with a 2 (probe location) $\times 5$ (ISI) $\times 3$ (target duration) repeated measures ANOVA. Overall, RT was faster $[F(1,9)=6.77, p<.03]$ for line motion judgments to $\mathrm{S} 1$ locations $(615 \mathrm{msec})$ than for those to locations opposite to $\mathrm{S} 1$ (686 msec), when a target appeared. There was also a significant main effect of ISI $[F(4,36)=3.28, p<.03]$. The results of planned comparisons are reported in Table A1.

\section{Experiment 2}

A 2 (probe location) $\times 5$ (ISI) repeated measures ANOVA applied to conditions lacking a target revealed only a main effect of ISI $[F(4,36)=17.91, p<.0005]$, reflecting a linear $[F(1,36)=17.91, p<.0002]$ increase in RT with increasing ISI. No other effects were present. A set of planned comparisons (see Table A2) revealed no difference in RT at all levels of ISI.

Table A 1

RTs to Observer Motion Judgments for Each Possible Stimulus Position and All Levels of ISI in Experiment 1 Along With Associated Planned Comparison Statistics (PCs)

\begin{tabular}{|c|c|c|c|c|c|c|}
\hline \multirow[b]{2}{*}{ ISI (msec) } & \multicolumn{3}{|c|}{ No Target } & \multicolumn{3}{|c|}{ Target Present } \\
\hline & $\begin{array}{c}\text { Same } \\
\text { Location }\end{array}$ & $\begin{array}{l}\text { Opposite } \\
\text { Location }\end{array}$ & $\begin{array}{c}\mathrm{PCs} \\
F(1,36)\end{array}$ & $\begin{array}{c}\text { Same } \\
\text { Location }\end{array}$ & $\begin{array}{l}\text { Opposite } \\
\text { Location }\end{array}$ & $\begin{array}{c}\mathrm{PCs} \\
F(1,72)\end{array}$ \\
\hline 0 & 635.90 & 712.65 & $6.53 \dagger$ & 623.784 & 722.540 & $37.08^{*}$ \\
\hline 100 & 594.16 & 686.73 & $9.50 \dagger$ & 593.856 & 683.050 & $30.25^{*}$ \\
\hline 300 & 615.89 & 675.87 & $3.99 \dagger$ & 607.193 & 685.027 & $23.03^{*}$ \\
\hline 500 & 640.21 & 666.40 & 0.76 & 607.884 & 662.024 & $11.14 \dagger$ \\
\hline 900 & 673.36 & 705.58 & 1.15 & 642.850 & 679.618 & $5.14+$ \\
\hline
\end{tabular}


Table A2

RTs to Observer Motion Judgments for Each Possible Stimulus Position and All Levels of ISI in Experiment 2, Along With Associated

Planned Comparison Statistics (PCs)

\begin{tabular}{ccccccc}
\hline & \multicolumn{3}{c}{ No Target } & \multicolumn{3}{c}{ Target Present } \\
\cline { 2 - 7 } ISI (msec) & $\begin{array}{c}\text { Same } \\
\text { Location }\end{array}$ & $\begin{array}{c}\text { Opposite } \\
\text { Location }\end{array}$ & $\begin{array}{c}\text { PCs } \\
F(1,36)\end{array}$ & $\begin{array}{c}\text { Same } \\
\text { Location }\end{array}$ & $\begin{array}{c}\text { Opposite } \\
\text { Location }\end{array}$ & $\begin{array}{c}\text { PCs } \\
F(1,72)\end{array}$ \\
\hline 0 & 620.28 & 619.64 & 0.01 & 651.263 & 656.828 & 0.17 \\
100 & 552.65 & 601.04 & 3.15 & 627.212 & 638.401 & 0.69 \\
300 & 611.03 & 629.29 & 0.45 & 652.482 & 675.000 & 2.78 \\
500 & 690.33 & 690.60 & 0.09 & 684.667 & 703.791 & 2.00 \\
900 & 706.90 & 695.00 & 0.19 & 723.258 & 745.086 & 2.61 \\
\hline
\end{tabular}

(Manuscript received June 20, 1995;

revision accepted for publication November 12, 1995.) 